\title{
A New Principle of Fault Identification of on the Same Tower Based on Traveling Wave Reactive Powers
}

\author{
Hao $W^{1}{ }^{*}$, Ruikai Ye ${ }^{1}$, Xingxing Dong1, Kunjian $Y^{1}{ }^{1}$, Zhengwei Chang ${ }^{2}$ \\ 1School of Electrical Automation and Information Engineering, Sichuan University of Science and Engineering, Zigong, China \\ ${ }^{2}$ Electric Power Research Institute, Sichuan Electric Power Company of China Power Grid, Chengdu, China \\ Email: *wuhao801212@163.com
}

How to cite this paper: $\mathrm{Wu}, \mathrm{H}$., Ye, R.K., Dong, X.X., Yu, K.J. and Chang, Z.W. (2019) A New Principle of Fault Identification of on the Same Tower Based on Traveling Wave Reactive Powers. Journal of Power and Energy Engineering, 7, 50-70. https://doi.org/10.4236/jpee.2019.77005

Received: June 24, 2019

Accepted: July 28, 2019

Published: July 31, 2019

Copyright $\odot 2019$ by author(s) and Scientific Research Publishing Inc. This work is licensed under the Creative Commons Attribution International License (CC BY 4.0).

http://creativecommons.org/licenses/by/4.0/

\begin{abstract}
In order to improve the reliability of fault identification of the double-circuit transmission lines on the same tower, a new algorithm for fast protection of double-circuit transmission lines on the same tower based on the reactive powers of traveling wave is proposed. With the implementation of S-transform, the initial traveling wave reactive powers are calculated and the change characteristics of reactive power under different fault conditions are studied. The protection criterion is constructed by analyzing the ratio of the reactive powers of the same end on double-circuit transmission lines and the ratio of the reactive powers at both ends on the same line. According to the ratio of reactive power on the same side of the line and both ends of the same line, it is possible to identify whether the faults of the double-circuit line of the same tower occurred in or out of the protection zone. A large number of simulation results show that the protection performance is sensitive and reliable, and quick to respond. The criterion is simple and is basically not affected by fault initial angles, fault types, and transitional resistances.
\end{abstract}

\section{Keywords}

Double-Circuit Transmission Line on the Same Tower, Traveling Wave Reactive Power, S-Transform, Fault Identification

\section{Introduction}

With the advantages of saving investment cost and effectively improving power transmission capacity, the double circuit transmission lines on the same tower have been widely used in China's high-voltage power grid in [1]. However, the distance between the double circuit transmission lines is short due to the sharing 
of the same tower, which leads to more complex inter-phase coupling and interline coupling compared with what happened to single circuit transmission line. The transmission line protection scheme on single circuit transmission line is not applicable to double circuit transmission lines on the same tower, so many scholars have made a lot of research on the protection scheme of the double circuit line on the same tower.

The literature [2]-[8] mainly studies the protection and the fault phase selection of the double circuit transmission lines on the same tower based on power frequency, which has a slight deficiency in the response time. In [9], a fault locating method using single-ended impedance is proposed, which has high robustness, however, when a cross-line fault of the same name occurs, the fault location accuracy rate was not high. The literature [10] uses the circuit line protection scheme of the single-ended transient main frequency to satisfy the requirement of rapidity, but its reliability depends on too many factors. The literature [11] proposed the concept of the modal differential transverse current, and quoted the concept of constructing the line fault diagnosis criterion, which can accurately identify the internal and external faults, but the ability to identify the complex faults is still insufficient. In [12], the fault current traveling wave characteristics on the double-circuit line on the same tower are analyzed, but no specific circuit protection scheme is proposed. The literature [13] used the characteristics of inconsistent traveling wave speeds when a metallic fault on the same tower occured and proposed a differential protection scheme for traveling wave on the same tower double circuit line. The sensitivity and rapidity of the scheme are relatively high.

Based on the research ideas of literature [14] [15] [16], this paper proposes a new fault identification principle based on reactive power of the traveling wave on double-circuit lines on the same tower. The S-transform is used to extract the single-frequency initial voltage and current traveling wave after the fault occurs. The initial traveling wave reactive power is calculated using initial voltage and current traveling wave. The fault identification principle identifies the internal and external faults according to the ratio of the reactive power of the same ends of the line and both the ends of the same line. The experimental simulation results show that the program provides a quick response, high identification accuracy and sensitivity.

\section{Analysis of Fault Current Traveling Wave of Double Circuit Line on The same Tower}

Figure 1 is the model of double-circuit lines on the same tower, busbar $\mathrm{M}$ and $\mathrm{N}$ are connected to the transmission lines, $\mathrm{MN}$ is the double-circuit line protection zone, $\mathrm{PM}$ section and $\mathrm{NO}$ section are outside the protection zone and $\mathrm{R}_{1} \sim \mathrm{R}_{6}$ are corresponding traveling wave protection units.

The forward direction of the traveling wave is defined as the direction from the bus to the double circuit. Taking the traveling wave protection unit $R_{1}$ as an example, suppose that $u$ and $i$ are respectively the voltage and current traveling 
waves detected by $R_{1}$. If $t_{0}$ is the traveling wave arrives at bus $M$ from the fault point for the first time, $t_{1}$ is the second time the traveling wave arrives at $\mathrm{M}$ after the wave reflection occurs, then the fault traveling wave acquired by $R_{1}$ is called the initial voltage and current traveling wave in time-slot $t_{0} \sim t_{1}$ in [14].

\subsection{Fault of Single-Circuit Transmission Line in the Area}

A fault occurs at point $K_{1}$ on the double-circuit line on the same tower, according to Peterson principle in [14], the fault feature can be simplified as shown in Figure 2, and Figure 2(a) \& Figure 2(b) are respectively models of traveling wave propagating to bus $\mathrm{M}$ and to bus $\mathrm{N} . \Delta \dot{I}_{k}(k=1,2,3,4,5,6)$ in the figure shows the fault current traveling wave detected by the corresponding traveling wave protection unit on the double-circuit line of the same tower; $\Delta \dot{U}_{M}$ and $\Delta \dot{U}_{N}$ are the initial voltage traveling wave on busbar $\mathrm{M}$ and busbar $\mathrm{N} ; Z_{c 1} \sim Z_{c 4}$ are respectively the corresponding wave impedance of line $L_{1} \sim L_{4}$, and $Z_{c M}$ and $Z_{c N}$ are the ground stray capacitance equivalent impedance of busbar $\mathrm{M}$ and busbar $\mathrm{N}$ respectively.

According to [14], in Peterson equivalent circuit, when the traveling wave frequency $f=50-100 \mathrm{kHz}$, the wave impedance of the extra (ultra) high-voltage transmission line approximates to a real constant and can be equivalent to resistance $R$. Therefore, the impedance in Figure 2 approximates to $Z_{c 1}=Z_{c 2}=Z_{c 3}=Z_{c 4} \approx R$. $Z_{c M}=1 / j \omega C_{M}=1 / j 2 \pi C_{M}$ is the ground equivalent capacitance wave impedance of the busbar. Take the direction in which the traveling wave propagates to the bus $\mathrm{M}$ as an example result at the equation of:

$$
\begin{gathered}
\Delta \dot{I}_{1}=-\frac{\Delta \dot{U}_{M}}{Z_{C 2} / / Z_{C 3} / / Z_{c M}} \approx-\Delta \dot{U}_{M} \cdot \frac{2+j \omega C_{M} R}{R} \\
\Delta \dot{I}_{2}=\frac{\Delta \dot{U}_{M}}{Z_{c 2}} \approx \frac{\Delta \dot{U}_{M}}{R}
\end{gathered}
$$

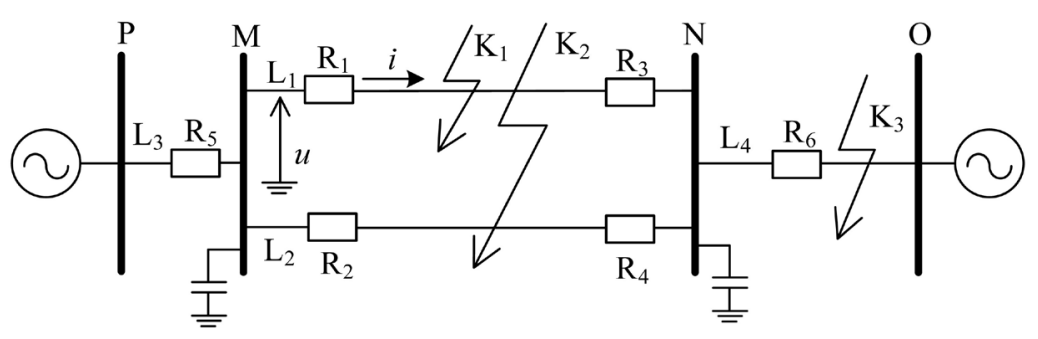

Figure 1. Simplified model of double-circuit transmission lines on the same tower.

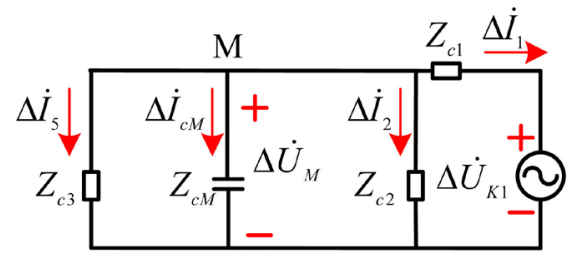

(a) Bus M Peterson model

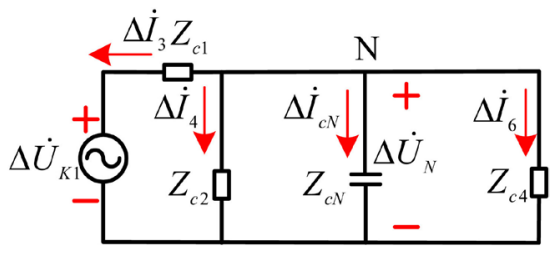

(b) Bus N Peterson model

Figure 2. Peterson model of single-line fault in the zone. 
According to circuit theory, the complex power $\tilde{S}=U \cdot I^{*}=P+j Q$, where $P$ is the active power and $Q$ is the reactive power, the traveling wave complex power obtained at the Bus $\mathrm{M}$ is:

$$
\left\{\begin{array}{l}
\tilde{S}_{1}=\Delta \dot{U}_{M} \cdot \Delta \dot{U}_{M}^{*} \approx-\frac{2 \Delta U_{M}^{2}}{R}+j \cdot \Delta U_{M}^{2} \cdot \omega C_{M}=P_{1}+j Q_{1} \\
\tilde{S}_{2}=\Delta \dot{U}_{M} \cdot \Delta \dot{I}_{N}^{*} \approx \frac{\Delta U_{M}^{2}}{R}=P_{2}+j Q_{2}
\end{array}\right.
$$

The corresponding initial traveling wave reactive power can be obtained as follows:

$$
\left\{\begin{array}{l}
Q_{1} \approx \Delta U_{M}^{2} \cdot \omega C_{M} \\
Q_{2} \approx 0
\end{array}\right.
$$

According to the calculation, the ratio of reactive power of the initial traveling wave on the $\mathrm{M}$ side of the double-circuit transmission line of the same tower is:

$$
\lambda=\frac{\max \left(\left|Q_{1}\right|,\left|Q_{2}\right|\right)}{\min \left(\left|Q_{1}\right|,\left|Q_{2}\right|\right)}=\frac{\Delta U_{M}^{2} \cdot \omega C_{M}}{0} \rightarrow \infty
$$

In other words, the reactive power ratio $\lambda$ of the double circuit transmission line on the same side is a large number when the single circuit fault occurs in the fault area, and the fault can be clearly identified by utilizing this feature.

\subsection{Same Name Phase Cross Line Ground Faults in the Area}

A same-name phase cross line ground fault occurs at point $K_{2}$ on the same-tower double-circuit line. The Peterson model of the transmission line is shown in Figure 3.

The traveling wave of each current can be obtained as follows:

$$
\left\{\begin{array}{l}
\Delta \dot{I}_{k}=-\frac{1}{2} \cdot \frac{\Delta \dot{U}_{K_{2}}}{\left(Z_{c 3} / / Z_{c M}+Z_{c 1} / / Z_{c 2}\right)}=-\frac{\Delta \dot{U}_{K_{2}}\left(1+j \omega C_{M} R\right)}{3 R+j \omega C_{M} R^{2}}(k=1,2) \\
\Delta \dot{U}_{k}=-\frac{1}{2} \cdot \frac{\Delta \dot{U}_{K_{2}}}{\left(Z_{c 4} / / Z_{c N}+Z_{c 1} / / Z_{c 2}\right)}=-\frac{\Delta \dot{U}_{K_{2}}\left(1+j \omega C_{N} R\right)}{3 R+j \omega C_{N} R^{2}}(k=3,4)
\end{array}\right.
$$

The complex power of the transmission line is:

$$
\left\{\begin{aligned}
\tilde{S}_{k} & =\Delta \dot{U}_{K_{2}} \cdot \Delta \dot{U}_{k}^{*}=P_{k}+j Q_{k}(k=1,2) \\
& =-\frac{\Delta U_{K_{2}}^{2} \cdot\left(3 R+\omega^{2} C_{M}^{2} R^{3}\right)}{9 R^{2}+\omega^{2} C_{M}^{2} R^{4}}+j \cdot \frac{2 \Delta U_{K_{2}}^{2} \omega C_{M} R^{2}}{9 R^{2}+\omega^{2} C_{M}^{2} R^{4}} \\
\tilde{S}_{k} & =\Delta \dot{U}_{K_{2}} \cdot \Delta \dot{I}_{k}^{*}=P_{k}+j Q_{k}(k=3,4) \\
& =-\frac{\Delta U_{K_{2}}^{2} \cdot\left(3 R+\omega^{2} C_{M}^{2} R^{3}\right)}{9 R^{2}+\omega^{2} C_{N}^{2} R^{4}}+j \cdot \frac{2 \Delta U_{K_{2}}^{2} \omega C_{N} R^{2}}{9 R^{2}+\omega^{2} C_{N}^{2} R^{4}}
\end{aligned}\right.
$$

The reactive power of the same end of the double circuit line is:

$$
\operatorname{BusM}\left\{\begin{array}{l}
Q_{1}=Q_{2} \approx \frac{2 \Delta U_{K_{2}}^{2} \omega C_{M} R^{2}}{9 R^{2}+\omega^{2} C_{M}^{2} R^{4}} \\
Q_{3}=Q_{4} \approx \frac{2 \Delta U_{K_{2}}^{2} \omega C_{N} R^{2}}{9 R^{2}+\omega^{2} C_{N}^{2} R^{4}}
\end{array}\right.
$$




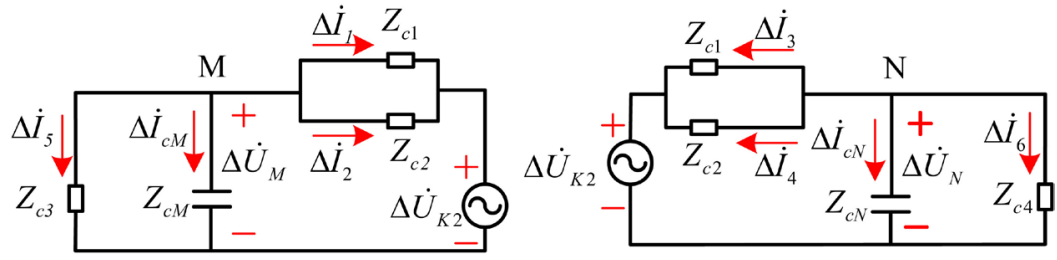

(a) Bus M Peterson model

(b) Bus N Peterson model

Figure 3. Peterson model of Same-name phase cross line ground fault in protection zone

The reactive powers on the same side of the line are approximately equal. And the ratio of the reactive powers is approximately one.

Take line $\mathrm{L}_{1}$ as an example, the reactive power ratio at both ends of the same line can be derived as:

$$
\begin{aligned}
\lambda & =\frac{\max \left(\left|Q_{1}\right|,\left|Q_{3}\right|\right)}{\min \left(\left|Q_{1}\right|,\left|Q_{3}\right|\right)}=\frac{2 \Delta U_{K_{2}}^{2} \omega C_{M} R^{2}}{9 R^{2}+\omega^{2} C_{M}^{2} R^{4}} \cdot \frac{9 R^{2}+\omega^{2} C_{N}^{2} R^{4}}{2 \Delta U_{K_{2}}^{2} \omega C_{N} R^{2}} \\
& =\frac{C_{M}\left(9+\omega^{2} C_{N}^{2} R^{2}\right)}{C_{N}\left(9+\omega^{2} C_{M}^{2} R^{2}\right)}
\end{aligned}
$$

In formula (9), the value of $\lambda$ is determined by the ground capacitance of busbar. Ideally, the ground capacitance of busbar at both ends of the double circuit transmission line are about the same size, so $\lambda \approx 1$.

\subsection{Fault out the Area}

When a fault occurs at point $\mathrm{K}_{3}$ outside the protection zone, the line fault feature can be simplified to the Peterson model of Figure 4.

Each current traveling wave can be expressed as:

$$
\left\{\begin{array}{l}
\Delta \dot{I}_{k}=-\frac{1}{2} \cdot \frac{\Delta \dot{U}_{N}}{\left(Z_{c 3} / / Z_{c M}+Z_{c 1} / / Z_{c 2}\right)} \approx-\frac{\Delta \dot{U}_{N}\left(1+j \omega C_{M} R\right)}{3 R+j \omega C_{M} R^{2}}(k=1,2) \\
\Delta \dot{I}_{k}=\frac{\Delta \dot{U}_{N}}{Z_{c k}} \approx \frac{\Delta \dot{U}_{N}}{R}(k=3,4)
\end{array}\right.
$$

The complex power on the line can be expressed as:

$$
\left\{\begin{aligned}
\tilde{S}_{k} & =\Delta \dot{U}_{N} \cdot \Delta \dot{I}_{k}^{*}=P_{k}+j Q_{k}(k=1,2) \\
& =-\frac{\Delta U_{N}^{2} \cdot\left(3 R+\omega^{2} C_{M}^{2} R^{3}\right)}{9 R^{2}+\omega^{2} C_{M}^{2} R^{4}}+j \cdot \frac{2 \Delta U_{N}^{2} \omega C_{M} R^{2}}{9 R^{2}+\omega^{2} C_{M}^{2} R^{4}} \\
\tilde{S}_{k} & =\Delta \dot{U}_{N} \cdot \Delta \dot{I}_{k}^{*}=\frac{\Delta U_{N}^{2}}{R}=P_{k}+j Q_{k}(k=3,4)
\end{aligned}\right.
$$

When a fault occurs outside the protection zone, the reactive power of the

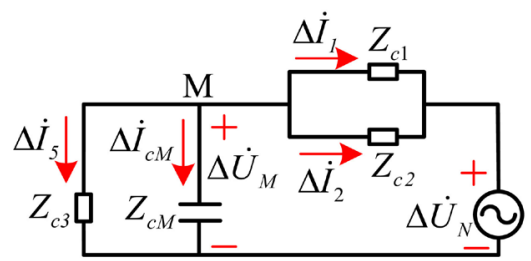

(a) Bus M Peterson model

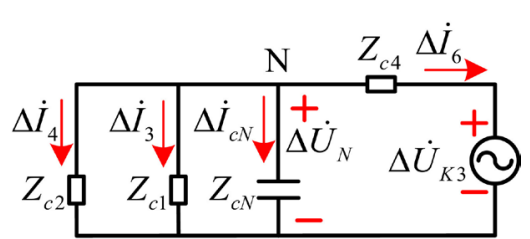

(b) Bus N Peterson model

Figure 4. Peterson model of a fault occurred outside the zone. 
traveling wave can be derived as:

$$
\left\{\begin{array}{l}
Q_{1}=Q_{2} \approx \frac{2 \Delta U_{N}^{2} \omega C_{M} R^{2}}{9 R^{2}+\omega^{2} C_{M}^{2} R^{4}} \\
Q_{3}=Q_{4} \approx 0
\end{array}\right.
$$

The traveling wave reactive powers on the same end of the double-circuit transmission line on the same tower are approximately equal. Taking line L1 as an example, the reactive power ratio of initial travelling wave at both ends of the line is:

$$
\lambda=\frac{\max \left(\left|Q_{1}\right|,\left|Q_{3}\right|\right)}{\min \left(\left|Q_{1}\right|,\left|Q_{3}\right|\right)}=\frac{\frac{2 \Delta U_{N}^{2} \omega C_{M} R^{2}}{9 R^{2}+\omega^{2} C_{M}^{2} R^{4}}}{0} \rightarrow \infty
$$

When a fault occurs out of the protection zone, the reactive power on the bus near the fault location is approximately zero, and the reactive power of the busbar on the far side of fault location is non-zero. The reactive power ratio at both ends of the same line is a large number.

Based on the above analysis, it can be seen that when a fault occurs out of the protection zone, 1) the reactive power of traveling wave on the same side is approximately equal; 2) the ratio of reactive power of traveling wave on both ends of the same line is relatively large.

\section{Algorithm Implementation}

\subsection{Phase Mode Transformation}

There is a more complicated coupling in the double-circuit transmission line of the same tower than that of a single-circuit transmission line. There is coupling between the phases and between the lines, so the phase-mode transformation must be implemented to decouple before calculating the fault components. This paper chooses the decoupling transformation matrix resembling Clarke transformation matrix $M$ in [2].

$$
M=\left[\begin{array}{cccccc}
1 & 1 & 1 & 0 & 0 & 0 \\
1 & 1 & -\frac{1}{2} & \frac{\sqrt{3}}{2} & 0 & 0 \\
1 & 1 & -\frac{1}{2} & -\frac{\sqrt{3}}{2} & 0 & 0 \\
1 & -1 & 0 & 0 & 1 & 0 \\
1 & -1 & 0 & 0 & -\frac{1}{2} & \frac{\sqrt{3}}{2} \\
1 & -1 & 0 & 0 & -\frac{1}{2} & -\frac{\sqrt{3}}{2}
\end{array}\right]
$$

The relationship between the six-phase current I and the modulus current $I_{m}$ on the double-circuit transmission line on the same tower is:

$$
I_{m}=M^{-1} I
$$


In the formula, the components represented by $I$ and $I_{m}$ are:

$$
\begin{aligned}
I_{m} & =\left[\begin{array}{llllll}
I_{\mathrm{I} 0} & I_{\mathrm{II} 0} & I_{\mathrm{I} \alpha} & I_{\mathrm{II} \alpha} & I_{\mathrm{I} \beta} & I_{\mathrm{II} \beta}
\end{array}\right] \\
I & =\left[\begin{array}{llllll}
I_{\mathrm{IA}} & I_{\mathrm{IB}} & I_{\mathrm{IC}} & I_{\mathrm{IIA}} & I_{\mathrm{IIB}} & I_{\mathrm{IIC}}
\end{array}\right]
\end{aligned}
$$

Similarly, relationship between the corresponding six-phase voltage $U$ and the modulus voltage $U_{m}$ is:

$$
U_{m}=M^{-1} U
$$

In the formula, the components represented by $U$ and $U_{m}$ are:

$$
\begin{aligned}
U_{m} & =\left[\begin{array}{llllll}
U_{\mathrm{I} 0} & U_{\mathrm{II} 0} & U_{\mathrm{I} \alpha} & U_{\mathrm{I} \beta} & U_{\mathrm{II} \alpha} & U_{\mathrm{II} \beta}
\end{array}\right] \\
U & =\left[\begin{array}{llllll}
U_{\mathrm{IA}} & U_{\mathrm{IB}} & U_{\mathrm{IC}} & U_{\mathrm{IIA}} & U_{\mathrm{IIB}} & U_{\mathrm{IIC}}
\end{array}\right]
\end{aligned}
$$

In the formula, $0, \alpha, \beta$ respectively represent the zero-modulus, $\alpha$-modulus, and $\beta$-modulus components after the phase-mode transformation is implemented; subscripts I and II denote the I-circuit and the II-circuit transmission line of the double-circuit line on the same tower respectively.

\subsection{S-Transform}

S-transform is a method of signal time-frequency joint analysis, and it is the development of continuous wavelet transform and short-time Fourier transform. Assume the discrete time sequence of the signal $h(t)$ is $h[k T](k=0,1,2, \cdots, N-1)$, where $T$ is the time interval, and the discrete Fourier transform of $h[k T]$ is

$$
H\left[\frac{n}{N T}\right]=\frac{1}{N} \sum_{k=0}^{N-1} h[k T] \mathrm{e}^{-\mathrm{j} \frac{2 \pi n k}{N}}
$$

where $n=0,1, \cdots, N-1$.

When $n \neq 0$, the discrete $S$ transform of time sequence $h[k T]$ can be derived as:

$$
S\left[k T, \frac{n}{N T}\right]=\sum_{r=0}^{N-1} H\left[\frac{r+n}{N T}\right] \mathrm{e}^{-\frac{2 \pi^{2} r^{2}}{n^{2}}} \mathrm{e}^{\mathrm{j} \frac{2 \pi r k}{N}}
$$

When $n=0$, the discrete transformation of time series $h[k T]$ is a constant, which can be derived as:

$$
S[k T, 0]=\frac{1}{N} \sum_{r=0}^{N-1} h\left(\frac{r}{N T}\right)
$$

In formula (23), $k, n=0,1, \cdots, N-1$. A two-dimensional time-frequency matrix of the signal $h[k T]$ is obtained with the implementation of S-transform. The rows in this matrix correspond to the sampling time of the signal and the columns correspond to discrete frequencies.

Because S-transform has good signal extraction characteristics in time-frequency analysis, this paper uses S-transform to extract fault current traveling wave and voltage traveling wave. Based on this, the corresponding complex power and reactive power are calculated. 


\subsection{Calculation of Initial Traveling Wave Reactive Power}

Take the three-phase grounding fault occurred at point $\mathrm{K}_{1}$ on line $\mathrm{L}_{1}$ in Figure 1 as an example. The fault current component is detected on protection unit $\mathrm{R}_{1}$, and $\Delta i_{1}$ is the combined-modulus current obtained using phase-mode transformation. Discrete S-transform is performed on the current modulus $\Delta i_{1}$ according to Equations (22) and (23). One-dimensional complex phasor is obtained at selected frequency $f_{Z}$ [14], which can be derived as:

$$
\Delta \dot{I}_{\mathrm{I}}\left(t, f_{Z}\right)=\Delta I_{\mathrm{I}} \exp \left[j \theta_{\Delta I_{\mathrm{I}}}\right]
$$

where $\Delta I_{\mathrm{I}}, \theta_{\Delta I_{\mathrm{I}}}$ are the amplitude and phasor of the $\Delta \dot{I}_{\mathrm{I}}\left(t, f_{Z}\right)$ respectively. If at the time $t_{1}$, the amplitude of the traveling wave head reaches a maximum value $\Delta I_{\text {max.1 }}$, the modulus current $\Delta \dot{I}_{\mathrm{I}}\left(t_{1}, f_{Z}\right)$ at this moment is the initial current traveling wave peak phasor at the selected frequency $f_{Z}$ in [16]. Similarly, the initial voltage traveling wave peak phasor $\Delta \dot{U}_{M}\left(t_{1}, f_{Z}\right)$ of busbar $\mathrm{M}$ can be determined. According to the calculation formula of complex frequency, the faulted initial traveling wave complex frequency on line $\mathrm{L}_{1}$ near $\mathrm{M}$ terminal can be obtained as:

$$
\tilde{S}_{\mathrm{I}}=\Delta \dot{U}_{M} \cdot \Delta \dot{I}_{\mathrm{I}}^{*}=P_{1}+j Q_{1}=\Delta U_{M} \cdot \Delta I_{\mathrm{I}} \exp \left[j\left(\theta_{\Delta U_{M}}-\theta_{\Delta I_{\mathrm{I}}}\right)\right]
$$

$Q_{1}$ is the fault initial traveling wave reactive power on line $\mathrm{L}_{1}$ on Busbar $\mathrm{M}$. Similarly, the initial traveling wave reactive power $Q_{2}, Q_{3}, Q_{4}$ on other protection units can be calculated in the double-circuit line on the same-tower.

Based on the derivation above, the initial traveling wave reactive power detected by each protection unit of the double-circuit line on the same tower under different fault types can be calculated by using the initial traveling wave peak phasor obtained at the selected single frequency with the supplementation of S-transform.

PSCAD software was used to simulate the faults of $K_{1}-K_{3}$. The fault data was imported into MATLAB for decoupling and S-transform. The corresponding waveform of the initial voltage and current traveling wave and initial traveling wave reactive power of protection units $R_{1}-R_{4}$ were obtained.

For the single-circuit $\mathrm{L}_{1}$ fault in double-circuit line on the same tower, the waveform of the initial voltage and current traveling wave and the waveform of the initial traveling wave reactive powers are shown in Figure 5 and Figure 6 respectively.

Analysis of Figure 5 shows that when a single circuit transmission line fault occurs in the protection zone, the reactive power of fault line $\mathrm{L}_{1}$ detected at bus $\mathrm{M}$ of the double-circuit line on the same tower is much greater than that of the non-fault transmission line $\mathrm{L}_{2}$. Similarly, the reactive power of the fault line $\mathrm{L}_{1}$ detected at the bus $\mathrm{N}$ is also greater than that of the non-fault line $\mathrm{L}_{2}$.

In the case of the same-name phase cross line ground fault within double-circuit transmission line on the same tower, the waveform of the initial travelling wave reactive powers are shown in Figure 7 and Figure 8 respectively. The analysis 


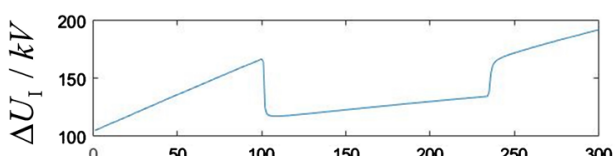

(a) I circuit line $M$ terminal voltage initial

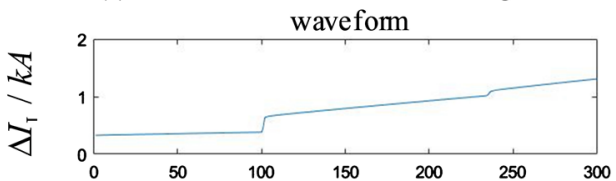

(c) I circuit line $M$ terminal current initial

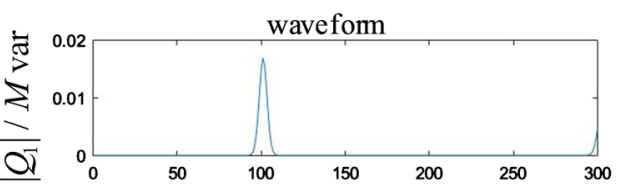

(e) I circuit line $M$ terminal initial wave reactive power

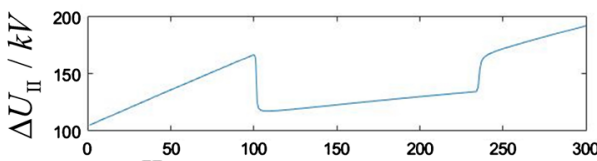

(b) II circuit line $M$ terminal voltage

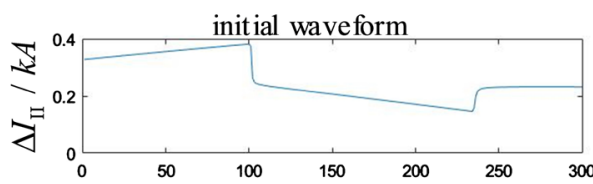

(d) II circuit line $M$ terminal current initial

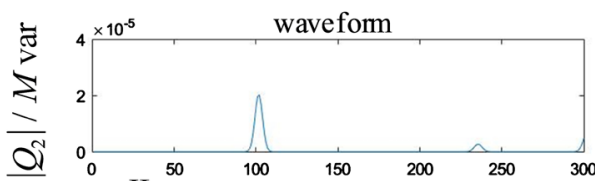

(f) II circuit line $M$ terminal initial wave reactive power

Figure 5. Waveform of single-circuit $\mathrm{L}_{1}$ fault in the protection zone at Bus M.

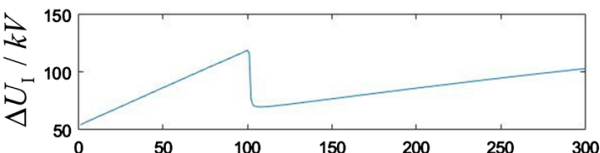

(a) I circuit line $\mathrm{N}$ terminal voltage initial

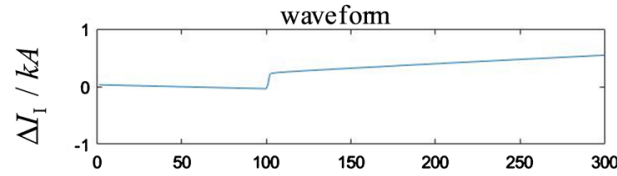

(c) I circuit line $\mathrm{N}$ terminal current initial

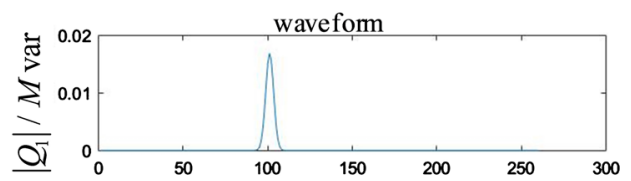

(e) I circuit line $\mathrm{N}$ terminal initial wave reactive power

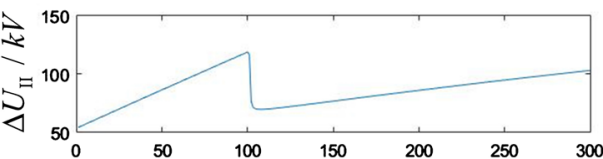

(b) II circuit line $\mathrm{N}$ terminal voltage initial waveform

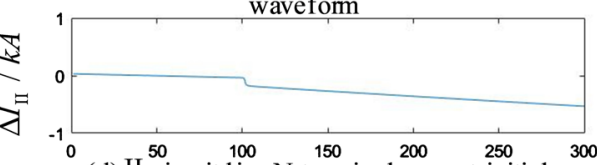

(d) II circuit line N terminal current initial

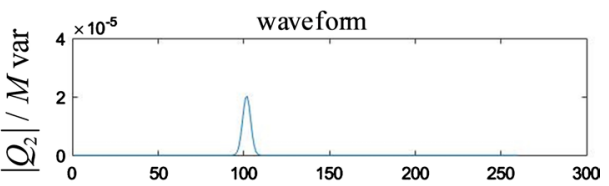

(f) II circuit line $\mathrm{N}$ terminal initial wave react ive power

Figure 6. Waveform of single-circuit $\mathrm{L}_{1}$ fault in the protection zone at Bus N.

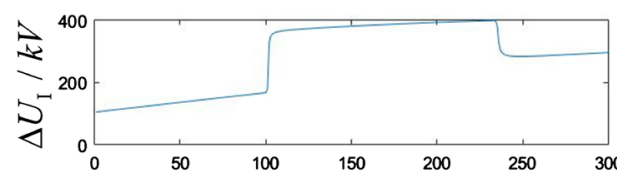

(a) I circuit line $M$ terminal initial voltage

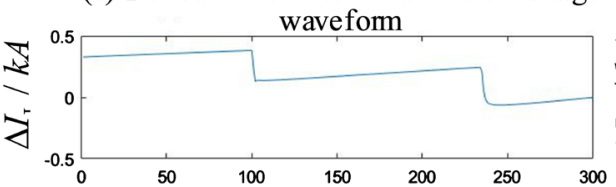

(c) I circuit line $M$ terminal initial current waveform

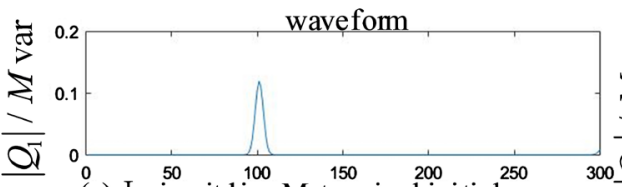

(e) I circuit line M terminal initial wave

reactive power

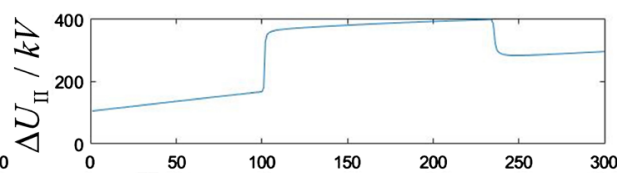

(b) II circuit line $M$ terminal initial voltage waveform

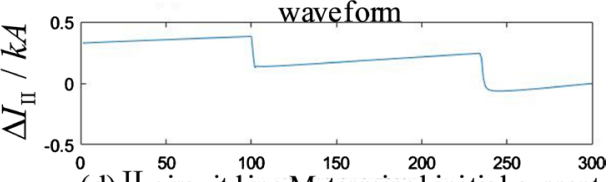

(d) II circuit line $\mathrm{M}^{150}$ terminal initial current waveform

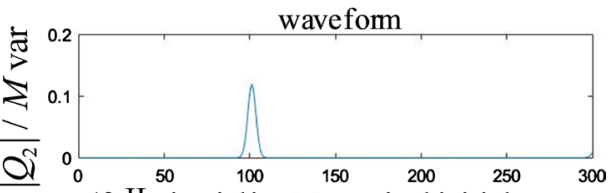

(f) II circuit line $M$ terminal initial wave reactive power

Figure 7. Waveform of same-name phase cross line ground fault in protection zone at Bus M. 


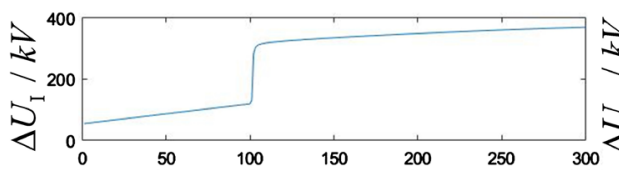

(a) I circuit line $\mathrm{N}$ terminal initial voltage waveform

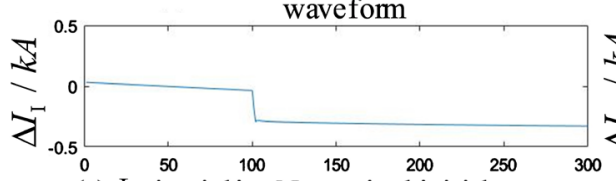

(c) I circuit line $\mathrm{N}$ terminal initial current wave form

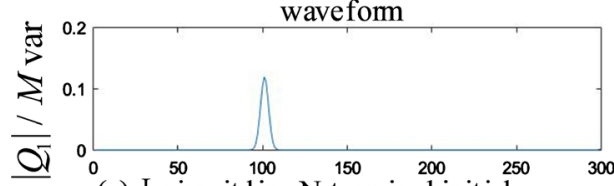

(c) I circuit line $\mathrm{N}$ terminal initial wave reactive power

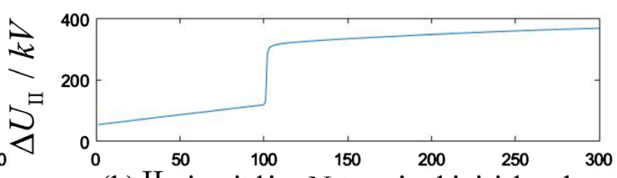

(b) II circuit line $\mathrm{N}$ terminal initial voltage waveform

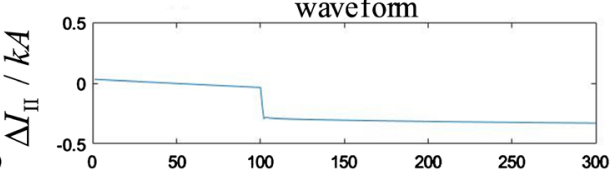

(d) II circuit line $\mathrm{N}$ terminal initial current waveform

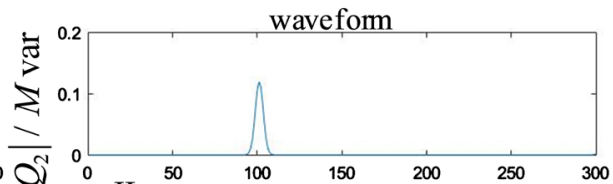

(f) II circuit line $\mathrm{N}$ terminal initial wave reactive power

Figure 8. Waveform of same-name phase cross line ground fault in protection zone at Bus N.

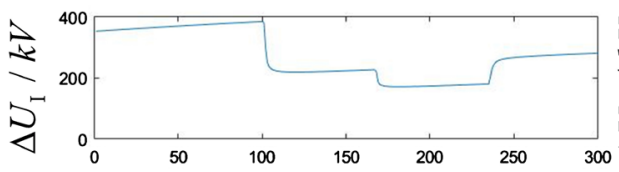

(a) I circuit line $M$ terminal initial voltage waveform

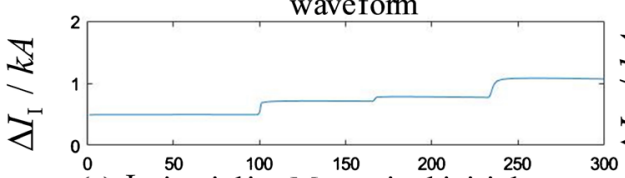

(c) I circuit line $M$ terminal initial current wave form

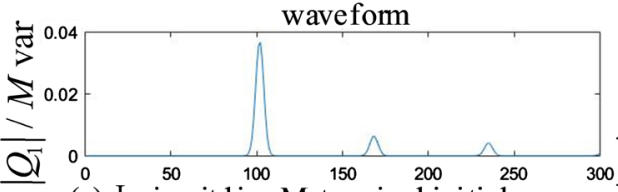

(e) I circuit line $M$ terminal initial wave reactive power

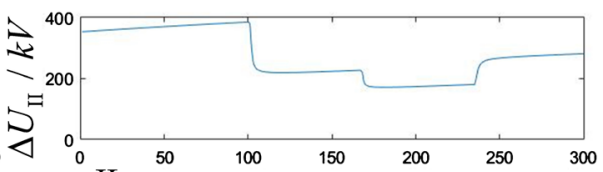

(b) II circuit line M terminal initial voltage waveform

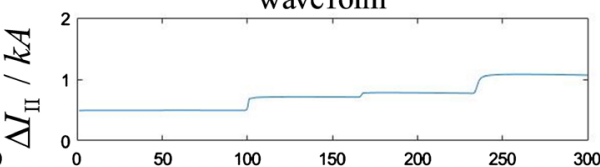

(d) II circuit line $M$ terminal initial current

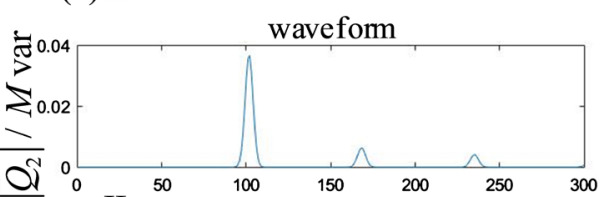

(f) II circuit line M terminal initial wave reactive power

Figure 9. Waveform of the fault out of the protection zone at Bus M.

shows that the reactive power detected on the same end of the double circuit line is approximately equal, and the reactive power detected on both the ends of the same line is approximately equal.

When a fault occurs at point $\mathrm{K}_{3}$ of the double-circuit line on the same tower, the waveform of the initial travelling wave reactive powers are shown in Figure 9 and Figure 10 respectively. Analysis of Figure 9 and Figure 10 shows that when a fault occurs out of the protection zone, the traveling wave reactive power on the same side of the double circuit line is approximately equal, and the reactive powers of the traveling wave at both ends of the same line vary significantly, and the reactive power of the traveling wave of the busbar near the fault is much greater than that of the traveling wave of the busbar far from the fault.

Based on the analysis above, when a fault occurs on the single-circuit transmission line in the protection zone, the ratio of the reactive power at the same 


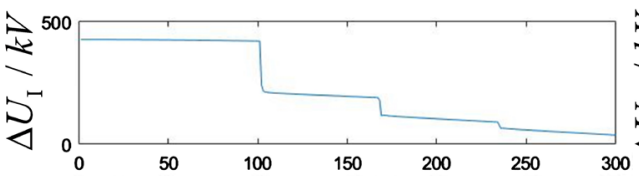

(a) I circuit line $\mathrm{N}$ terminal initial voltage waveform

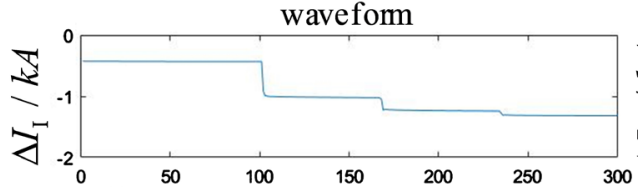

(c) I circuit line $\mathrm{N}$ terminal initial current

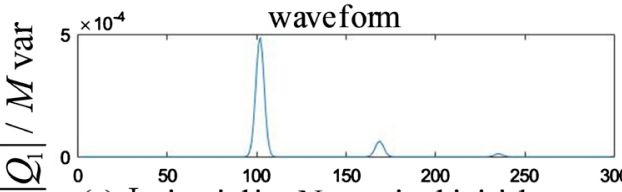

(e) I circuit line $\mathrm{N}$ terminal initial wave reactive power

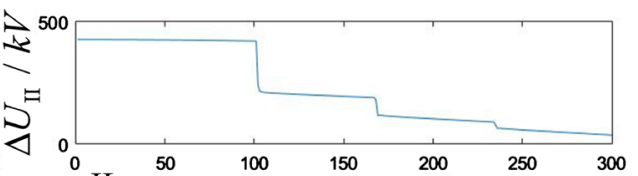

(b) II circuit line $\mathrm{N}$ terminal initial voltage waveform

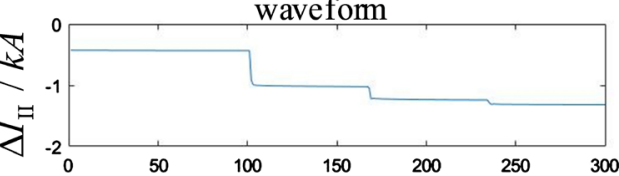

(b) II circuit line $\mathrm{N}$ terminal initial current

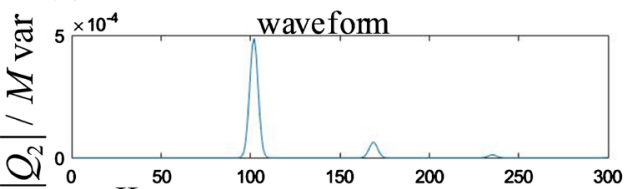

(f) II circuit line $\mathrm{N}$ terminal initial wave reactive power

Figure 10. Waveform of the fault out of the protection zone at Bus N.

end of the two lines is big. When the same-name phase cross-line ground fault occurs in the protection zone, the reactive powers of the traveling wave of the same end of the two lines and both the ends of the same line are similar. When a fault occurs out of the protection zone, the reactive power of the same end of the two lines is approximately equal and the ratio is approximately 1 ; and the reactive power of the initial traveling wave at both the ends of the same line varies greatly, the ratio of the reactive powers is a large value. These changing characteristics of the reactive powers can be used to identify faults which occurred in or out the protection zone.

\section{Establishment of Criterion}

In order to accurately identify the faults occurred double circuit transmission line on the same tower, the reactive power ratios of the traveling wave on the same side of the two lines and the traveling wave reactive power ratios of the two ends of the same line on the double-circuit line on the same tower are calculated to construct the primary criterion and secondary criterion for fault identification.

\subsection{Primary Criterion for Fault Identification}

Take the system of Figure 1 as an example. The initial traveling wave reactive power measured by the four traveling wave protection units $R_{1} \sim R_{4}$ on the same-tower double-circuit transmission line is $Q_{1} \sim Q_{4}$, and the ratio of the initial traveling wave reactive power on the same side of double-circuit line on the same tower is:

$$
\left\{\begin{array}{l}
\lambda_{M}=\frac{\max \left\{\left|Q_{1}\right|,\left|Q_{2}\right|\right\}}{\min \left\{\left|Q_{1}\right|,\left|Q_{2}\right|\right\}} \\
\lambda_{N}=\frac{\max \left\{\left|Q_{3}\right|,\left|Q_{4}\right|\right\}}{\min \left\{\left|Q_{3}\right|,\left|Q_{4}\right|\right\}}
\end{array}\right.
$$


The primary criterion established for the ratio of the initial traveling wave reactive power on the same side of double-circuit line on the same-tower is:

$$
\left\{\begin{array}{l}
\lambda_{M}>\lambda_{S E T-S} \\
\lambda_{N}>\lambda_{S E T-S}
\end{array}\right.
$$

In the equation, $\lambda_{S E T-S}$ is the threshold value, and $\lambda_{S E T-S}=50$ tentatively. When the initial traveling wave reactive power ratio $\lambda_{k}(k=\mathrm{M}, \mathrm{N})$ at the same end of the double-circuit line satisfies the primary criterion (27), it can be concluded that an internal fault occurs.

According to statistical data, when a fault occurs, the probability that a fault would occur on a single-circuit transmission line is much greater than that of a cross-line fault. The frequency of cross-line faults is only $2 \%-3 \%$ of the total number of faults on the same-tower double-circuit transmission line in [17]. Therefore, with the primary criterion, most faults occurred on double-circuit line on the same-tower in the protection zone can be identified.

\subsection{Secondary Criterion for Fault Identification}

If the ratio of the initial traveling wave reactive powers on the same end of the double-circuit line on the same-tower cannot satisfy the primary criterion, the secondary criterion is invoked. The ratio is calculated using the initial traveling wave reactive powers at both ends of the same line according to the secondary criterion:

$$
\left\{\begin{array}{c}
\rho_{\mathrm{I}}=\frac{\max \left\{\left|Q_{1}\right|,\left|Q_{3}\right|\right\}}{\min \left\{\left|Q_{1}\right|,\left|Q_{3}\right|\right\}} \\
\rho_{\mathrm{II}}=\frac{\max \left\{\left|Q_{2}\right|,\left|Q_{4}\right|\right\}}{\min \left\{\left|Q_{2}\right|,\left|Q_{4}\right|\right\}}
\end{array}\right.
$$

In the formula, $\rho_{\mathrm{I}}$ and $\rho_{\mathrm{II}}$ represent the initial reactive wave reactive power ratios at both ends of the I circuit line and both ends of the II circuit line of the double-circuit line on the same tower. The comparison criterion of the initial traveling wave reactive power ratio of the two ends of the same line on the double-circuit line on the same-tower is:

$$
\left\{\begin{array}{l}
\rho_{\mathrm{I}}<\rho_{S E T-D} \\
\rho_{\mathrm{II}}<\rho_{S E T-D}
\end{array}\right.
$$

In the criterion, $\rho_{S E T-D}$ is the threshold value, and $\rho_{S E T-D}=100$ tentatively. Therefore, when the reactive power ratio of the traveling wave at both ends of the same line $\rho_{k}(k=\mathrm{I}, \mathrm{II})$ satisfies the secondary criterion (29), it can be concluded that a fault occurs in the protection zone, otherwise, a fault occurs out of the zone.

\subsection{Algorithm Flow}

When a fault traveling wave occurs on the double circuit transmission line on the same tower, the $\alpha$-modulus and $\beta$-modulus of the corresponding voltage and 
current are obtained through phase mode transformation. According to the literature [2], when the line protection device detects that the fault is a single-phase fault or two phases, same-name phases cross line grounding fault, $\boldsymbol{\alpha}$-modulus is selected for S-transform, and $\beta$-modulus is selected to identify other faults.

Time-frequency transformation is performed on the selected modulus with the implementation of S-transform. The single-frequency fault initial voltage traveling wave and current traveling wave corresponding to $60 \mathrm{kHz}$ are selected with the implementation of S-transform in [14], and the corresponding initial traveling wave reactive power is calculated.

Primary and secondary criteria are used to achieve fault recognition of double-circuit line on the same tower, and the fault identification algorithm flow is shown in Figure 11.

\section{Simulation Verification}

In this paper, PSCAD software is used to establish the simulation model of double-circuit transmission lines on the same tower. The total length of the line

Read the original data of the three phase voltage and current on the same side of the same tower double circuit transmission line

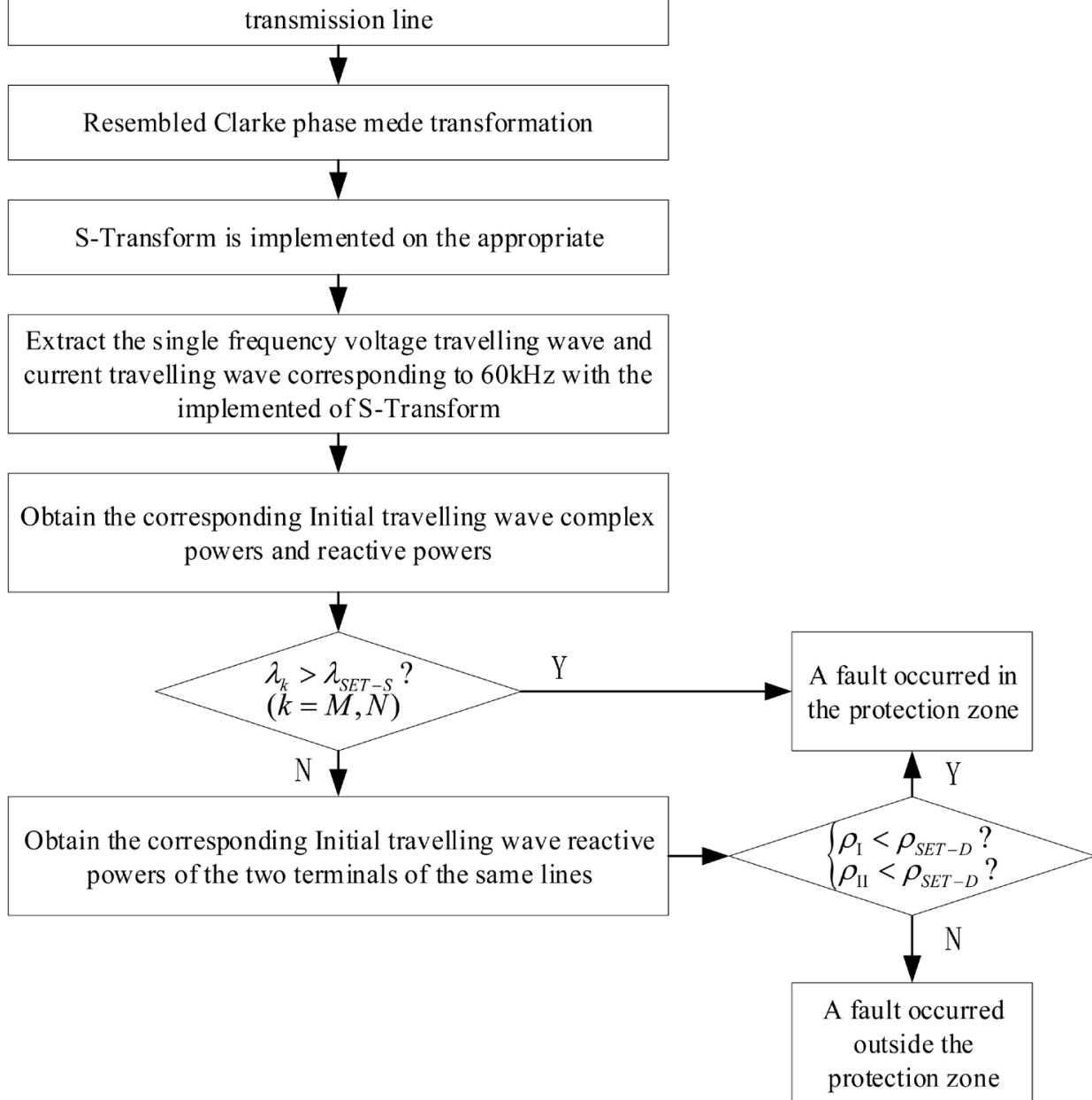

Figure 11. Flow of fault recognition algorithm for double-circuit lines on the same tower. 
is $300 \mathrm{~km}$. Both of the voltages at bus $\mathrm{M}$ and bus $\mathrm{N}$ are $500 \mathrm{kV}$ and the frequency $50 \mathrm{~Hz}$. The location of the protection unit is as shown in Figure 1. The line parameters of the double-circuit lines on the same tower is Tower:3L12. The line parameter used for the single-circuit line is Tower: $3 \mathrm{H} 5$, and the sampling frequency is set as $200 \mathrm{kHz}$.

\subsection{Faults Occurred in the Protection Zone}

A single-phase ground fault occurred on the double-circuit transmission line on the same tower. Take AB phase grounded fault occurred on the I circuit transmission line as an example. The fault location is $100 \mathrm{~km}$ away from bus $\mathrm{N}$, the transitional resistance is $500 \Omega$, the fault initial angle is $45^{\circ}$, and the diagrammatic map of the current traveling wave on the transmission line is shown in Fig 2. According to the criteria of this paper, after calculating the initial traveling wave reactive power with the implementation of S-transform, the ratio of the traveling wave reactive power at bus $\mathrm{M}$ is $\lambda_{M} \approx 8.5593 \times 10^{2}$, and the ratio of the traveling wave reactive power at bus $\mathrm{N}$ is $\lambda_{N} \approx 8.5590 \times 10^{2}$, and both reactive power ratios satisfy the primary criterion (27), thus it can be judged as a fault occurred in the protection zone. In order to verify the effectiveness of the algorithm in the protection zone of fault identification, a lot of simulation tests are carried out in this paper.

Table 1 shows the fault simulation of the double-circuit line on the same tower in the protection zone under different fault types. From the analysis in Table 1, it can be seen that a secondary criterion (29) is needed for the same-name

Table 1. Identification result of protection algorithm under different fault types when an internal fault occurs on double-circuit transmission line on the same tower.

\begin{tabular}{|c|c|c|c|c|c|c|c|c|}
\hline \multirow{3}{*}{ Fault location } & \multirow{3}{*}{ Fault type } & \multirow{3}{*}{ circuit } & \multicolumn{5}{|c|}{ The data of reactive power } & \multirow{3}{*}{$\begin{array}{c}\text { Identification } \\
\text { result }\end{array}$} \\
\hline & & & $Q_{1}(\mathrm{kvar})$ & \multirow{2}{*}{$\lambda_{M}$} & $Q_{3}(\mathrm{kvar})$ & \multirow{2}{*}{$\lambda_{N}$} & $\rho_{\mathrm{I}}$ & \\
\hline & & & $Q_{2}(\mathrm{kvar})$ & & $Q_{4}(\mathrm{kvar})$ & & $\rho_{\mathrm{II}}$ & \\
\hline \multirow{12}{*}{$\begin{array}{l}\text { A fault occurs at a } \\
\text { distance of } 100 \mathrm{~km} \text { from } \\
\text { bus } \mathrm{N} \text {; fault initial angel is } \\
90^{\circ} \text {; transitional resistance } \\
\text { is } 200 \Omega\end{array}$} & \multirow{2}{*}{ IIAG } & I circuit & $1.2481 \mathrm{e}-03$ & \multirow{2}{*}{$8.9816 e+02$} & $1.2489 \mathrm{e}-03$ & \multirow{2}{*}{$8.9752 \mathrm{e}+02$} & & Internal fault \\
\hline & & II circuit & 1.1210 & & 1.1210 & & & Internal fault \\
\hline & \multirow{2}{*}{ IBC } & I circuit & $1.6898 \mathrm{e}+01$ & \multirow{2}{*}{$8.5339 e+02$} & $1.6898 \mathrm{e}+01$ & \multirow{2}{*}{$8.5333 e+02$} & & Internal fault \\
\hline & & II circuit & $1.9801 \mathrm{e}-02$ & & $1.9802 \mathrm{e}-02$ & & & Internal fault \\
\hline & \multirow{2}{*}{ IBCIIA } & I circuit & $1.6898 \mathrm{e}+01$ & \multirow{2}{*}{$8.5339 \mathrm{e}+02$} & $1.6898 \mathrm{e}+01$ & \multirow{2}{*}{$8.5333 \mathrm{e}+02$} & & Internal fault \\
\hline & & II circuit & $1.9801 \mathrm{e}-02$ & & $1.9802 \mathrm{e}-02$ & & & Internal fault \\
\hline & \multirow{2}{*}{ ICIICG } & I circuit & 3.5440 & \multirow{2}{*}{1.0000} & 3.5440 & \multirow{2}{*}{1.0000} & 1.0000 & Internal fault \\
\hline & & II circuit & 3.5440 & & 3.5440 & & 1.0000 & Internal fault \\
\hline & \multirow{2}{*}{ IABIIAB } & I circuit & $1.1951 \mathrm{e}+02$ & \multirow{2}{*}{1.0000} & $1.1951 \mathrm{e}+02$ & \multirow{2}{*}{1.0000} & 1.0000 & Internal fault \\
\hline & & II circuit & $1.1951 \mathrm{e}+02$ & & $1.1951 \mathrm{e}+02$ & & 1.0000 & Internal fault \\
\hline & \multirow{2}{*}{$\begin{array}{c}\text { IABC } \\
\text { IIABCG }\end{array}$} & I circuit & $3.3745 \mathrm{e}+01$ & \multirow{2}{*}{1.0000} & $3.3745 \mathrm{e}+01$ & \multirow{2}{*}{1.0000} & 1.0000 & Internal fault \\
\hline & & II circuit & $3.3745 \mathrm{e}+01$ & & $3.3745 \mathrm{e}+01$ & & 1.0000 & Internal fault \\
\hline
\end{tabular}


phases cross-line fault, while other cross-line faults and single-circuit faults only need to use the primary criterion (27) to identify the fault in the protection zone. Using these two criteria, the algorithm will not misjudge under different types of faults.

From Table 2, we can see that the ratio of the traveling wave reactive powers of the same side of the line is high with small fault initial angle, and it satisfies the primary criterion (27). When a complex cross-line fault occurs, the reactive powers of the same side of the line are not affected by the fault initial angle, but the ratio is approximately 1 , and the primary criterion (27) cannot be satisfied. The secondary criterion (29) is needed to calculate the ratio of the traveling wave reactive power of both ends of the same-tower double-circuit line. The calculation result satisfies the secondary criterion, which shows that the protection algorithm can accurately identify the faults occurred in the protection zone with different fault initial angles.

Table 2. Identification result of protection algorithm under different fault initial angles when an internal fault occurs on double-circuit transmission line on the same tower.

\begin{tabular}{|c|c|c|c|c|c|c|c|c|}
\hline \multirow{3}{*}{ Fault location } & \multirow{3}{*}{$\begin{array}{c}\text { Fault } \\
\text { initial } \\
\text { angle }\left(^{\circ}\right)\end{array}$} & \multirow{3}{*}{ circuit } & \multicolumn{5}{|c|}{ The data of reactive power } & \multirow{3}{*}{$\begin{array}{c}\text { Identification } \\
\text { result }\end{array}$} \\
\hline & & & $Q_{1}$ (kvar) & \multirow{2}{*}{$\lambda_{M}$} & $Q_{3}($ kvar $)$ & \multirow{2}{*}{$\lambda_{N}$} & $\rho_{\mathrm{I}}$ & \\
\hline & & & $Q_{2}($ kvar $)$ & & $Q_{4}(\mathrm{kvar})$ & & $\rho_{\text {II }}$ & \\
\hline \multirow{10}{*}{$\begin{array}{l}\text { IB short circuit grounding } \\
\text { occurs at a distance of } 100 \\
\mathrm{~km} \text { from bus } \mathrm{N} \text {; transitional } \\
\text { resistance is } 100 \Omega\end{array}$} & \multirow{2}{*}{5} & I circuit & 2.3130 & \multirow{2}{*}{$6.1383 e+03$} & 3.5310 & \multirow{2}{*}{$6.8516 \mathrm{e}+03$} & & Internal fault \\
\hline & & II circuit & $3.7678 \mathrm{e}-04$ & & $5.1538 \mathrm{e}-04$ & & & Internal fault \\
\hline & \multirow{2}{*}{15} & I circuit & 7.2890 & \multirow{2}{*}{$7.1642 \mathrm{e}+03$} & $1.0309 \mathrm{e}+01$ & \multirow{2}{*}{$7.6187 e+03$} & & Internal fault \\
\hline & & II circuit & $1.0175 \mathrm{e}-03$ & & $1.3531 \mathrm{e}-03$ & & & Internal fault \\
\hline & \multirow{2}{*}{45} & I circuit & $3.2971 \mathrm{e}+01$ & \multirow{2}{*}{$6.0546 \mathrm{e}+02$} & $8.1263 e+01$ & \multirow{2}{*}{$9.9396 \mathrm{e}+02$} & & Internal fault \\
\hline & & II circuit & $5.4455 \mathrm{e}-02$ & & $8.1756 \mathrm{e}-02$ & & & Internal fault \\
\hline & \multirow{2}{*}{90} & I circuit & $4.8094 \mathrm{e}+01$ & \multirow{2}{*}{$6.0523 e+02$} & $1.1858 \mathrm{e}+02$ & \multirow{2}{*}{$9.9373 e+02$} & & Internal fault \\
\hline & & II circuit & $7.9464 \mathrm{e}-02$ & & $1.1933 \mathrm{e}-01$ & & & Internal fault \\
\hline & \multirow{2}{*}{120} & I circuit & $5.9774 \mathrm{e}+01$ & \multirow{2}{*}{$1.3467 \mathrm{e}+03$} & $4.4028 \mathrm{e}+01$ & \multirow{2}{*}{$7.6884 \mathrm{e}+02$} & & Internal fault \\
\hline & & II circuit & $4.4387 \mathrm{e}-02$ & & $5.7266 \mathrm{e}-02$ & & & Internal fault \\
\hline \multirow{10}{*}{$\begin{array}{l}\text { IABC and IIBC short circuit } \\
\text { occurs at a distance of } 200 \\
\mathrm{~km} \text { from bus } \mathrm{N}\end{array}$} & \multirow{2}{*}{5} & I circuit & $4.1562 \mathrm{e}+02$ & \multirow{2}{*}{1.0000} & $7.6294 \mathrm{e}+02$ & \multirow{2}{*}{1.0000} & 1.8357 & Internal fault \\
\hline & & II circuit & $4.1562 \mathrm{e}+02$ & & $7.6294 \mathrm{e}+02$ & & 1.8357 & Internal fault \\
\hline & \multirow{2}{*}{15} & I circuit & $6.8018 \mathrm{e}+02$ & \multirow{2}{*}{1.0000} & $3.4090 \mathrm{e}+02$ & \multirow{2}{*}{1.0000} & 1.9953 & Internal fault \\
\hline & & II circuit & $6.8018 \mathrm{e}+02$ & & $3.4090 \mathrm{e}+02$ & & 1.9953 & Internal fault \\
\hline & \multirow{2}{*}{45} & I circuit & $5.0482 \mathrm{e}+02$ & \multirow{2}{*}{1.0000} & $2.0542 \mathrm{e}+02$ & \multirow{2}{*}{1.0000} & 2.4575 & Internal fault \\
\hline & & II circuit & $5.0482 \mathrm{e}+02$ & & $2.0542 \mathrm{e}+02$ & & 2.4575 & Internal fault \\
\hline & & I circuit & $7.1952 \mathrm{e}+01$ & & $2.9354 \mathrm{e}+01$ & & 2.4512 & Internal fault \\
\hline & (20 & II circuit & $7.1952 \mathrm{e}+01$ & 1.0000 & $2.9354 \mathrm{e}+01$ & 1.0000 & 2.4512 & Internal fault \\
\hline & & I circuit & $4.5798 \mathrm{e}+02$ & & $6.2128 \mathrm{e}+02$ & & 1.3566 & Internal fault \\
\hline & & II circuit & $4.5798 \mathrm{e}+02$ & & $6.2128 \mathrm{e}+02$ & & 1.3566 & Internal fault \\
\hline
\end{tabular}


It can be seen from the analysis in Table 3 that when the transitional resistance and the fault location change, the primary criterion (27) still can be met with the ratio of the traveling wave reactive power, and it hardly changes with the change of transitional resistance, that is, the algorithm is not affected by the change of transitional resistance.

The above analysis shows that with different fault initial angles, transitional resistances, fault types, and fault locations, the simulation data is consistent with the theoretical analysis results, which means the protection can accurately reflect the faults occurred in the protection zone and operate in a reliable way.

\subsection{Faults Occurred Out of the Protection Zone}

A fault occurred out of the protection zone on the double circuit line on the same tower. Take the $\mathrm{BC}$ phase short-circuit fault out of the protection zone as an example. The fault location is $100 \mathrm{~km}$ from bus $\mathrm{N}$, and the fault initial angle is $90^{\circ}$. According to the criteria of this paper, after calculating the initial traveling wave reactive power with the implementation of S-transform, the ratio $\lambda_{M} \approx 1.0000$ of reactive power at the bus $\mathrm{M}$ can be obtained, the ratio of reactive power at the bus $\mathrm{N}$ is $\lambda_{N} \approx 1.0000$, and the ratio does not satisfy the primary criterion (27), so the secondary criterion is needed. The criterion uses the ratio of reactive

Table 3. Identification result of protection algorithm under different transitional resistances and fault locations when an internal fault occurs on double-circuit transmission line on the same tower

\begin{tabular}{|c|c|c|c|c|c|c|c|c|}
\hline \multirow{3}{*}{ Fault location } & \multirow{3}{*}{$\begin{array}{l}\text { Transitional } \\
\text { resistance } / \Omega\end{array}$} & \multirow{3}{*}{ circuit } & \multicolumn{5}{|c|}{ The data of reactive power } & \multirow{3}{*}{$\begin{array}{l}\text { Identification } \\
\text { result }\end{array}$} \\
\hline & & & $Q_{1}$ (kvar) & \multirow{2}{*}{$\lambda_{M}$} & $Q_{3}($ kvar $)$ & \multirow{2}{*}{$\lambda_{N}$} & $\rho_{\mathrm{I}}$ & \\
\hline & & & $Q_{2}(\mathrm{kvar})$ & & $Q_{4}(\mathrm{kvar})$ & & $\rho_{\mathrm{II}}$ & \\
\hline \multirow{8}{*}{$\begin{array}{l}\text { IIAC short circuit grounding } \\
\text { occurs at a distance of } 50 \mathrm{~km} \\
\text { from bus N; fault initial angle } \\
\text { is } 45^{\circ}\end{array}$} & \multirow{2}{*}{0} & I circuit & $2.7233 \mathrm{e}-05$ & \multirow{2}{*}{$8.5505 e+02$} & $2.7231 \mathrm{e}-05$ & \multirow{2}{*}{$8.5509 \mathrm{e}+02$} & & Internal fault \\
\hline & & II circuit & $2.3285 e-02$ & & $2.3285 \mathrm{e}-02$ & & & Internal fault \\
\hline & \multirow{2}{*}{100} & I circuit & $7.6425 \mathrm{e}-03$ & \multirow{2}{*}{$8.4949 e+02$} & $7.6416 \mathrm{e}-03$ & \multirow{2}{*}{$8.4958 \mathrm{E}+02$} & & Internal fault \\
\hline & & II circuit & 6.4920 & & 6.4920 & & & Internal fault \\
\hline & \multirow{2}{*}{300} & I circuit & $1.5208 \mathrm{e}-02$ & \multirow{2}{*}{$8.5388 \mathrm{e}+02$} & $1.5206 \mathrm{e}-02$ & \multirow{2}{*}{$8.5395 \mathrm{E}+02$} & & Internal fault \\
\hline & & II circuit & $1.2985 \mathrm{e}+01$ & & $1.2985 \mathrm{e}+01$ & & & Internal fault \\
\hline & \multirow{2}{*}{600} & I circuit & $1.9714 \mathrm{e}-02$ & \multirow{2}{*}{$8.5468 \mathrm{e}+02$} & $1.9713 \mathrm{e}-02$ & \multirow{2}{*}{$8.5474 \mathrm{E}+02$} & & Internal fault \\
\hline & & II circuit & $1.6850 \mathrm{e}+01$ & & $1.6850 \mathrm{e}+01$ & & & Internal fault \\
\hline \multirow{8}{*}{$\begin{array}{l}\text { IABIIC short circuit } \\
\text { grounding occurs at a distance } \\
\text { of } 250 \mathrm{~km} \text { from bus N; fault } \\
\text { initial angle is } 45^{\circ}\end{array}$} & \multirow{2}{*}{0} & I circuit & 8.7770 & \multirow{2}{*}{2.2532} & $2.2522 \mathrm{e}+01$ & \multirow{2}{*}{2.3305} & 2.5660 & Internal fault \\
\hline & & II circuit & $1.9776 \mathrm{e}+01$ & & $5.2487 \mathrm{e}+01$ & & 2.6541 & Internal fault \\
\hline & \multirow{2}{*}{100} & I circuit & 8.7770 & \multirow{2}{*}{2.2532} & $2.2522 \mathrm{e}+01$ & \multirow{2}{*}{2.3305} & 2.5660 & Internal fault \\
\hline & & II circuit & $1.9776 \mathrm{e}+01$ & & $5.2487 e+01$ & & 2.6541 & Internal fault \\
\hline & \multirow{2}{*}{300} & I circuit & 8.7770 & \multirow{2}{*}{2.2532} & $2.2522 \mathrm{e}+01$ & \multirow{2}{*}{2.3305} & 2.5660 & Internal fault \\
\hline & & II circuit & $1.9776 \mathrm{e}+01$ & & $5.2487 \mathrm{e}+01$ & & 2.6541 & Internal fault \\
\hline & \multirow{2}{*}{600} & I circuit & 8.7770 & \multirow{2}{*}{2.2532} & $2.2522 \mathrm{e}+01$ & \multirow{2}{*}{2.3305} & 2.5660 & Internal fault \\
\hline & & II circuit & $1.9776 \mathrm{e}+01$ & & $5.2487 \mathrm{e}+01$ & & 2.6541 & Internal fault \\
\hline
\end{tabular}


power at both ends of the same line, the ratio of reactive power at both ends of the I circuit line is $\rho_{\mathrm{I}} \approx 2.3013 \times 10^{2}$, and the ratio of reactive power at both ends of the II circuit line is $\rho_{\text {II }} \approx 2.3013 \times 10^{2}$, which does not meet the secondary criterion (29), so it can be concluded that the fault occurs out of the protection zone.

In order to fully verify the effectiveness of fault identification algorithm out of the protection zone, a lot of simulation experiments have been carried out.

Table 4 shows the fault simulation of double-circuit lines on the same tower out of the protection zone under different fault types. From the analysis of Table 4 , we can see that in the different fault locations and fault types, and comparing the initial traveling wave reactive power detected by the protection unit of double-circuit line on the same tower, the primary criterion (27) and secondary criterion (29) cannot be met, which shows that the algorithm can accurately identify faults occurred out of the protection zone under different fault types.

Table 5 shows that when a fault occurs out of the protection zone, the ratio of the traveling wave reactive power on the same side of the double-circuit line of the same tower is approximately the same when a fault occurs out of the protection zone, and the ratio remains constant at about 1 , which does not satisfy the primary criterion (27). Therefore the secondary criterion (29) is needed; on the same transmission line, the reactive powers of the busbar far from the fault point is higher than the reactive power at that of the busbar near the fault point, so the ratios of the reactive powers are relatively high, and all remain at 100 or more. Which not satisfy the secondary criterion (29) and it can be concluded that the

Table 4. Identification result of protection algorithm under different fault types when an external fault occurs on double-circuit transmission line on the same tower

\begin{tabular}{|c|c|c|c|c|c|c|c|c|}
\hline \multirow{3}{*}{ Fault location } & \multirow{3}{*}{ Fault type } & \multirow{3}{*}{ circuit } & \multicolumn{5}{|c|}{ The data of reactive power } & \multirow{3}{*}{$\begin{array}{l}\text { Identification } \\
\text { result }\end{array}$} \\
\hline & & & $Q_{1}($ kvar $)$ & \multirow{2}{*}{$\lambda_{M}$} & $Q_{3}(\mathrm{kvar})$ & \multirow{2}{*}{$\lambda_{N}$} & $\rho_{\mathrm{I}}$ & \\
\hline & & & $Q_{2}$ (kvar) & & $Q_{4}($ kvar $)$ & & $\rho_{\mathrm{II}}$ & \\
\hline \multirow{6}{*}{$\begin{array}{l}\text { fault occurs on line } \mathrm{L}_{4} \text { at a } \\
\text { distance of } 50 \mathrm{~km} \text { from bus } \mathrm{N} \text {; } \\
\text { transitional resistance is } 200 \Omega \text {; } \\
\text { fault initial angle is } 15^{\circ}\end{array}$} & \multirow{2}{*}{ CG } & I circuit & 1.8190 & \multirow{2}{*}{1.0000} & $6.1816 \mathrm{e}-03$ & \multirow{2}{*}{1.000} & $2.9426 \mathrm{e}+02$ & External fault \\
\hline & & II circuit & 1.8190 & & $6.1816 \mathrm{e}-03$ & & $2.9426 \mathrm{e}+02$ & External fault \\
\hline & \multirow{2}{*}{ BCG } & I circuit & $1.0422 \mathrm{e}+02$ & \multirow{2}{*}{1.0000} & $5.6916 \mathrm{e}-01$ & \multirow{2}{*}{1.000} & $1.8312 \mathrm{e}+02$ & External fault \\
\hline & & II circuit & $1.0422 \mathrm{e}+02$ & & $5.6916 \mathrm{e}-01$ & & $1.8312 \mathrm{e}+02$ & External fault \\
\hline & \multirow{2}{*}{ ABCG } & I circuit & $1.0422 \mathrm{e}+02$ & \multirow{2}{*}{1.0000} & $5.6916 \mathrm{e}-01$ & \multirow{2}{*}{1.000} & $1.8312 \mathrm{e}+02$ & External fault \\
\hline & & II circuit & $1.0422 \mathrm{e}+02$ & & $5.6916 \mathrm{e}-01$ & & $1.8312 \mathrm{e}+02$ & External fault \\
\hline \multirow{6}{*}{$\begin{array}{l}\text { fault occurs on line } \mathrm{L}_{4} \text { at a } \\
\text { distance of } 100 \mathrm{~km} \text { from bus } \mathrm{N} \text {; } \\
\text { transitional resistance is } 500 \Omega \text {; } \\
\text { fault initial angle is } 120^{\circ}\end{array}$} & \multirow{2}{*}{ CG } & I circuit & $8.8781 \mathrm{e}-01$ & \multirow{2}{*}{1.0000} & $3.3912 \mathrm{e}-03$ & \multirow{2}{*}{1.000} & $2.6180 \mathrm{e}+02$ & External fault \\
\hline & & II circuit & $8.8781 \mathrm{e}-01$ & & $3.3912 \mathrm{e}-03$ & & $2.6180 \mathrm{e}+02$ & External fault \\
\hline & \multirow{2}{*}{ BCG } & I circuit & $4.1618 \mathrm{e}+01$ & \multirow{2}{*}{1.0000} & $1.5589 \mathrm{e}-01$ & \multirow{2}{*}{1.000} & $2.6697 \mathrm{e}+02$ & External fault \\
\hline & & II circuit & $4.1618 \mathrm{e}+01$ & & $1.5589 \mathrm{e}-01$ & & $2.6697 e+02$ & External fault \\
\hline & \multirow{2}{*}{$\mathrm{ABCG}$} & I circuit & $4.1619 \mathrm{e}+01$ & \multirow{2}{*}{1.0000} & $1.5589 \mathrm{e}-01$ & \multirow{2}{*}{1.000} & $2.6698 \mathrm{e}+02$ & External fault \\
\hline & & II circuit & $4.1619 \mathrm{e}+01$ & & $1.5589 \mathrm{e}-01$ & & $2.6698 \mathrm{e}+02$ & External fault \\
\hline
\end{tabular}


Table 5. Identification result of protection algorithm under different fault initial angles when an external fault occurs on double-circuit transmission line on the same tower.

\begin{tabular}{|c|c|c|c|c|c|c|c|c|}
\hline \multirow{3}{*}{ Fault location } & \multirow{3}{*}{$\begin{array}{c}\text { Fault initial } \\
\text { angle } /\left(^{\circ}\right)\end{array}$} & \multirow{3}{*}{ circuit } & \multicolumn{5}{|c|}{ The data of reactive power } & \multirow{3}{*}{$\begin{array}{c}\text { Identification } \\
\text { result }\end{array}$} \\
\hline & & & $Q_{1}(\mathrm{kvar})$ & \multirow{2}{*}{$\lambda_{M}$} & $Q_{3}(\mathrm{kvar})$ & \multirow{2}{*}{$\lambda_{N}$} & $\rho_{\mathrm{I}}$ & \\
\hline & & & $Q_{2}(\mathrm{kvar})$ & & $Q_{4}(\mathrm{kvar})$ & & $\rho_{\mathrm{II}}$ & \\
\hline \multirow{10}{*}{$\begin{array}{l}\text { A phase grounded short } \\
\text { circuit occurs on line } \mathrm{L}_{4} \text { at a } \\
\text { distance of } 50 \mathrm{~km} \text { from bus } \\
\mathrm{N} \text {; transitional resistance is } \\
100 \Omega\end{array}$} & \multirow{2}{*}{5} & I circuit & $8.2278 \mathrm{e}-01$ & \multirow{2}{*}{1.0000} & $3.2481 \mathrm{e}-03$ & \multirow{2}{*}{1.000} & $2.5331 \mathrm{e}+05$ & External fault \\
\hline & & II circuit & $8.2278 \mathrm{e}-01$ & & $3.2481 \mathrm{e}-03$ & & $2.5331 \mathrm{e}+05$ & External fault \\
\hline & \multirow{2}{*}{15} & I circuit & $3.5450 \mathrm{e}+00$ & \multirow{2}{*}{1.0000} & $1.2243 \mathrm{e}-02$ & \multirow{2}{*}{1.000} & $2.8955 \mathrm{e}+05$ & External fault \\
\hline & & II circuit & $3.5450 \mathrm{e}+00$ & & $1.2243 \mathrm{e}-02$ & & $2.8955 \mathrm{e}+05$ & External fault \\
\hline & \multirow{2}{*}{45} & I circuit & $9.9380 \mathrm{e}+00$ & \multirow{2}{*}{1.0000} & $5.3274 \mathrm{e}-02$ & \multirow{2}{*}{1.000} & $1.8654 \mathrm{e}+05$ & External fault \\
\hline & & II circuit & 9.9380 & & $5.3274 \mathrm{e}-02$ & & $1.8654 \mathrm{e}+05$ & External fault \\
\hline & \multirow{2}{*}{90} & I circuit & $2.8121 \mathrm{e}+01$ & \multirow{2}{*}{1.0000} & $1.2000 \mathrm{e}-01$ & \multirow{2}{*}{1.000} & $2.3433 e+05$ & External fault \\
\hline & & II circuit & $2.8121 \mathrm{e}+01$ & & $1.2000 \mathrm{e}-01$ & & $2.3433 \mathrm{e}+05$ & External fault \\
\hline & \multirow{2}{*}{120} & I circuit & $1.5383 e+01$ & \multirow{2}{*}{1.0000} & $9.2246 e-02$ & \multirow{2}{*}{1.000} & $1.6676 \mathrm{e}+05$ & External fault \\
\hline & & II circuit & $1.5383 \mathrm{e}+01$ & & $9.2246 \mathrm{e}-02$ & & $1.6676 \mathrm{e}+05$ & External fault \\
\hline \multirow{10}{*}{$\begin{array}{l}\text { AC phase grounded short } \\
\text { circuit occurs on line } \mathrm{L}_{4} \text { at a } \\
\text { distance of } 100 \mathrm{~km} \text { from bus } \\
\mathrm{N}\end{array}$} & \multirow{2}{*}{5} & I circuit & 5.1890 & \multirow{2}{*}{1.0000} & $2.0336 \mathrm{e}-02$ & \multirow{2}{*}{1.000} & $2.5516 \mathrm{e}+05$ & External fault \\
\hline & & II circuit & 5.1890 & & $9.2246 \mathrm{e}-02$ & & $5.6252 \mathrm{e}+04$ & External fault \\
\hline & \multirow{2}{*}{15} & I circuit & 1.4780 & \multirow{2}{*}{1.0000} & $5.0523 \mathrm{e}-03$ & \multirow{2}{*}{1.000} & $2.9254 \mathrm{e}+05$ & External fault \\
\hline & & II circuit & 1.4780 & & $5.0523 \mathrm{e}-03$ & & $2.9254 \mathrm{e}+05$ & External fault \\
\hline & \multirow{2}{*}{45} & I circuit & 5.1610 & \multirow{2}{*}{1.0000} & $2.1929 \mathrm{e}-02$ & \multirow{2}{*}{1.000} & $2.3535 \mathrm{e}+05$ & External fault \\
\hline & & II circuit & 5.1610 & & $2.1929 \mathrm{e}-02$ & & $2.3535 \mathrm{e}+05$ & External fault \\
\hline & & I circuit & $3.6353 e+01$ & & $1.5434 \mathrm{e}-01$ & & $2.3553 \mathrm{e}+05$ & External fault \\
\hline & & II circuit & $3.6353 \mathrm{e}+01$ & 1.0000 & $1.5434 \mathrm{e}-01$ & 1.000 & $2.3553 \mathrm{e}+05$ & External fault \\
\hline & & I circuit & $3.5642 \mathrm{e}+01$ & & $2.1201 \mathrm{e}-01$ & & $1.6812 \mathrm{e}+05$ & External fault \\
\hline & & II circuit & $3.5642 \mathrm{e}+01$ & 1.0000 & $2.1201 \mathrm{e}-01$ & 1.000 & $1.6812 \mathrm{e}+05$ & External fault \\
\hline
\end{tabular}

fault occurred out of the protection zone, and the algorithm is not affected by the initial angle of the fault.

Table 6 shows that when faults occur out of the protection zone under different conditions of transitional resistance, the reactive powers of traveling waves detected on the two circuits transmission line on the same side of the double circuit line on the same-tower are approximately equal, and the ratio of the reactive powers of the initial traveling waves detected at both ends of the same line is high, which does not meet the secondary criterion (29). With the increase of the transitional resistance, the ratio of the initial traveling wave reactive power is approximately the same, indicating that this algorithm is not affected by the change of the transitional resistance. When the fault location is different, the reactive power ratio varies with the fault distance, but the secondary fault (29) can still be used to identify the fault occurred out of the protection zone.

In summary, the algorithm can accurately identify faults occurred on the 
Table 6. Identification result of protection algorithm under different transitional resistances and fault locations when an external fault occurs on double-circuit transmission line on the same tower.

\begin{tabular}{|c|c|c|c|c|c|c|c|c|}
\hline \multirow{3}{*}{ Fault location } & \multirow{3}{*}{$\begin{array}{l}\text { Transitional } \\
\text { resistance } / \Omega\end{array}$} & \multirow{3}{*}{ circuit } & \multicolumn{5}{|c|}{ The data of reactive power } & \multirow{3}{*}{$\begin{array}{l}\text { Identification } \\
\text { result }\end{array}$} \\
\hline & & & $Q_{1}($ kvar $)$ & \multirow{2}{*}{$\lambda_{M}$} & $Q_{3}(\mathrm{kvar})$ & \multirow{2}{*}{$\lambda_{N}$} & $\rho_{\mathrm{I}}$ & \\
\hline & & & $Q_{2}(\mathrm{kvar})$ & & $Q_{4}(\mathrm{kvar})$ & & $\rho_{\mathrm{II}}$ & \\
\hline \multirow{8}{*}{$\begin{array}{l}\mathrm{B} \text { phase grounded short } \\
\text { circuit occurs on the line } \mathrm{L}_{4} \\
\text { at a distance of } 50 \mathrm{~km} \text { from } \\
\text { bus } \mathrm{N} \text {; fault initial angle is } \\
45^{\circ}\end{array}$} & \multirow[b]{2}{*}{0} & I circuit & $3.9568 \mathrm{e}+01$ & \multirow[b]{2}{*}{1.0000} & $1.6714 \mathrm{e}-01$ & \multirow[b]{2}{*}{1.000} & $2.3673 e+02$ & External fault \\
\hline & & II circuit & $3.9568 \mathrm{e}+01$ & & $1.6714 \mathrm{e}-01$ & & $2.3673 e+02$ & External fault \\
\hline & \multirow{2}{*}{100} & I circuit & $1.8789 \mathrm{e}+01$ & \multirow{2}{*}{1.0000} & $7.9512 \mathrm{e}-02$ & \multirow{2}{*}{1.000} & $2.3630 \mathrm{e}+02$ & External fault \\
\hline & & II circuit & $1.8789 \mathrm{e}+01$ & & $7.9512 \mathrm{e}-02$ & & $2.3630 \mathrm{e}+02$ & External fault \\
\hline & \multirow[b]{2}{*}{300} & I circuit & 7.1480 & \multirow[b]{2}{*}{1.0000} & $3.0298 \mathrm{e}-02$ & \multirow[b]{2}{*}{1.000} & $2.3593 e+02$ & External fault \\
\hline & & II circuit & 7.1480 & & $3.0298 \mathrm{e}-02$ & & $2.3593 e+02$ & External fault \\
\hline & \multirow{2}{*}{600} & I circuit & 2.8850 & \multirow{2}{*}{1.0000} & $1.2242 \mathrm{e}-02$ & \multirow{2}{*}{1.000} & $2.3566 \mathrm{e}+02$ & External fault \\
\hline & & II circuit & 2.8850 & & $1.2242 \mathrm{e}-02$ & & $2.3566 \mathrm{e}+02$ & External fault \\
\hline \multirow{8}{*}{$\begin{array}{l}\mathrm{AB} \text { phase grounded short } \\
\text { circuit occurs on the line } \mathrm{L}_{4} \\
\text { at a distance of } 100 \mathrm{~km} \\
\text { from bus } \mathrm{N} \text {; fault initial } \\
\text { angle is } 90^{\circ}\end{array}$} & \multirow{2}{*}{0} & I circuit & $1.0578 \mathrm{e}+01$ & \multirow{2}{*}{1.0000} & $5.6479 \mathrm{e}-02$ & \multirow{2}{*}{1.000} & $1.8729 \mathrm{e}+02$ & External fault \\
\hline & & II circuit & $1.0578 \mathrm{e}+01$ & & $5.6479 \mathrm{e}-02$ & & $1.8729 \mathrm{e}+02$ & External fault \\
\hline & \multirow{2}{*}{100} & I circuit & $1.4558 \mathrm{e}+01$ & \multirow{2}{*}{1.0000} & $7.7907 e-02$ & \multirow{2}{*}{1.000} & $1.8686 \mathrm{e}+02$ & External fault \\
\hline & & II circuit & $1.4558 \mathrm{e}+01$ & & $7.7907 e-02$ & & $1.8686 \mathrm{e}+02$ & External fault \\
\hline & \multirow{2}{*}{300} & I circuit & $1.7208 \mathrm{e}+01$ & \multirow{2}{*}{1.0000} & $9.2136 \mathrm{e}-02$ & \multirow{2}{*}{1.000} & $1.8677 \mathrm{e}+02$ & External fault \\
\hline & & II circuit & $1.7208 \mathrm{e}+01$ & & $9.2136 \mathrm{e}-02$ & & $1.8677 \mathrm{e}+02$ & External fault \\
\hline & \multirow{2}{*}{600} & I circuit & $1.8520 \mathrm{e}+01$ & \multirow{2}{*}{1.0000} & $9.9170 \mathrm{e}-02$ & \multirow{2}{*}{1.000} & $1.8675 \mathrm{e}+02$ & External fault \\
\hline & & II circuit & $1.8520 \mathrm{e}+01$ & & $9.9170 \mathrm{e}-02$ & & $1.8675 \mathrm{e}+02$ & External fault \\
\hline
\end{tabular}

double-circuit line on the same tower out of the protection zone, and is not affected by initial angles of faults, transitional resistances, and types of faults. The algorithm is accurate and reliable and shows no defect or malfunction. That is to say, the test results are identical with theoretical analysis results.

\section{Conclusions}

In this paper, the protection principle of the double-circuit transmission line on the same tower based on the ratio of the initial traveling wave reactive power is proposed. The characteristics of the initial traveling wave reactive power of double circuit line on the same tower in and out of the protection zone are analyzed. The phase mode transformation and S-transform are implemented. The ratios of the initial traveling wave reactive power on the same end of double lines and both terminal of single line are collected to identify faults occurred in and out of the protection zone. Simulation results show that:

1) The algorithm obtains the single-frequency initial traveling wave reactive powers with the implementation of S-transform. It can accurately identify faults occurred in or out of the protection zone at different initial angles of faults, different transitional resistances and different fault locations, and has strong an- 
ti-interference performance.

2) Based on simple criteria, the protection algorithm only uses the initial traveling wave reactive power, needs to collect a small amount of data and is quick in calculation.

\section{Acknowledgements}

This research was supported by the Project of Sichuan provincial science and Technology Department (Grant No. 2018GZDZX0043).

\section{Conflicts of Interest}

The authors declare no conflicts of interest regarding the publication of this paper.

\section{References}

[1] Bi, T.S., Li, W., Xu, Z.Y., et al. (2013) Single-Phase Grounding Distance Protection of Parallel Transmission Lines on Same Poles Based on Electric Quantities Data from Single Terminal and Single Line. Automation of Electric Power Systems, 37, 88-93.

[2] Suonan, J., Wu, Y., Song, G., et al. (2003) New Accurate Fault Location Algorithm for Parallel Lines on the Same Tower Based on Distribute Parameter. Proceedings of the CSEE, 23, 39-43.

[3] Li, W., Bi, T.S. and Yang, Q.X. (2011) Fault Phase Selection with Fault Component in Same-Tower Double-Circuit Lines Based on Correlation Analysis. Automation of Electric Power Systems, 35, 58-62.

[4] Liu, Q., Huang, S. and Wang, X. (2007) Phase Selector Based on Fault Component Current for Double-Circuit Transmission Lines on Single Tower. Automation of Electric Power Systems, 31, 53-57.

[5] Eissa, M.M. and Masoud, M. (2001) A Novel Digital Distance Relaying Technique for Transmission Line Protection. IEEE Transactions on Power Delivery, 16, 380-384. https://doi.org/10.1109/61.924814

[6] Zhang, H. and Huang, S. (2012) An Inter Line Fault Equivalent Algorithm for Common-Tower Double-Transmission Line with Narrow Line-to-Line Distance. Power System Protection and Control, 40, 56-61.

[7] Zhang, Z., Cong, W., Xiao, J., et al. (2017) Acceleration Scheme of Zero-Sequence Inverse-Time Overcurrent Protection for Double-Circuit Lines on the Same Tower. Electric Power Automation Equipment, 37, 159-165.

[8] Zhu, Y., Du, H. and Zhao, Q. (2017) Research on Phase Selection for Double-Circuit Lines on the Same Tower with Asymmetrical Parameters. Power System Protection and Control, 45, 133-139.

[9] Ramar, K., Low, H.S. and Ngu, E.E. (2015) One-End Impedance Based Fault Location in Double-Circuit Transmission Lines with Different Configurations. Electrical Power and Energy Systems, 64, 1159-1165. https://doi.org/10.1016/j.ijepes.2014.09.006

[10] Gao, X., Zhang, X., Zhang, B., et al. (2013) Research on HV Line Protection Relay Based on Characteristic of Main Transient Frequencies. Journal of Mechanical \& Electrical Engineering, 30, 98-101. 
[11] Fan, C., Yu, W. and Li, K.K. (2006) Protection Scheme for Double Lines on Same Tower Based on Transient Energy of Modal Differential Transervese Current. Power System Technology, 30, 69-74.

[12] Tan, J., Huang, Z., Yang, H., et al. (2004) Study on Travelling Wave Propagation in Double-Circuit Parallel Transmission Line. Proceedings of the CSEE, 24, 30-34.

[13] Zhang, W., He, B., Hong, G., et al. (2008) Traveling-Wave Differential Relay Scheme for Double-Circuit Parallel Lines on the Same Pole. Automation of Electric Power Systems, 32, 66-71.

[14] Wu, H., Li, Q. and Liu, W. (2005) A New Pilot Protection Algorithm Based on Traveling Wave Power for Transmission Lines. Automation of Electric Power Systems, 29, 51-54.

[15] Liu, X., Lin, S., He, Z. and Liao, K. (2013) A Novel Surge Impedance Directional Relay Based on S Transform. Proceedings of the CSEE, 33, 113-119.

[16] Liu, X., Lin, S., He, Z. and Zhao, J. (2014) S Transform Based Travelling Wave Phase Comparison Directional Relay. Power System Technology, 38, 744-749.

[17] Zhang, T., Yan, A., Zhao, Y., et al. (2008) Study of a New Relay Protection Scheme for Double-Circuit Lines on the Same Pole. Relay, 36, 16-19. 